\title{
Pharmacology of the coronary circulation
}

\author{
J. Christopher Sill MBBS
}

Until recently, the medical management of coronary artery disease consisted of depressing the heart's requirements for oxygen. Little thought was directed towards improving coronary blood flow as it was believed that atherosclerotic lesions were fixed, unchangeable obstructions. Attempts at pharmacological coronary dilatation were, therefore, considered futile. Within the last few years, these concepts have undergone radical revision. ${ }^{1-3}$ It is now recognized that coronary stenoses are not fixed but are capable of both dilatation and constriction and these changes can have dramatic effects on blood supply to the heart. Drugs that either dilate or prevent constriction of atherosclerotic coronary articles are, therefore, of value in patients with coronary artery disease. ${ }^{4,5}$ However, paradoxically, drugs that dilate distal intramyocardial coronary arterioles may have the opposite effect. Coronary arteriolar dilatation, in the presence of epicardial atherosclerosis, may exacerbate maldistribution of coronary blood flow and lead to ischaemia. ${ }^{2,3,6}$ This confusing picture is best understood by considering the composition of the coronary vascular system.

The coronary circulation consists of large proximal coronary arteries that branch and ultimately form an intramyocardial network of small arteries and arterioles. ${ }^{2-4,7}$ The arterioles become smaller metarterioles and they eventually form the capillary bed. Blood returns via the coronary venous system. There are major functional differences between the large proximal coronary arteries and the smaller downstream arterioles. The proximal coronary arteries are large bore, relatively thin-walled vessels that lie predominantly on the epicardial surface of the heart. These vessels serve to conduct blood from the aorta to the intramyocardial network of arterioles. They are transport vesse $\mathrm{s}^{2-4,7}$ and contribute little to the overall vascular resistance of the coronary system. They possess considerable reserve capacity and even when blood flow is maximal, such as during extreme exertion, they continue to conduct the much increased flow of blood without imposing resistance. It is these vessels which are visualized during coronary angiography, undergo coronary atherosclerosis and are bypassed during coronary artery surgery.

Distal, downstream to the epicardial coronary arteries is a system of smaller arteries, arterioles and metarterioles that end in precapillary sphincters. ${ }^{2-4,7}$ These vessels penetrate throughout the myocardium and are responsible for delivery of blood to the cardiac tissue and for appropriate distribution of blood flow within the myocardium. They are relatively thick-walled, having a thick smooth muscle coat.

At rest, in normal man, blood flow to the left ventricle is about 60 to $80 \mathrm{ml} / 100 \mathrm{~g}$ myocardium/minute. ${ }^{7}$ When myocardial oxygen requirements increase, the resistance vessels dilate and permit myocardial flow to increase in proportion to demand. When oxygen rcquirements decrease, arterioles constrict and limit flow. For example, the subendocardium has a high metabolic rate yet coronary flow is restricted during systole because of a "throttling" effect of myocardial contraction on intramyocardial vessels. ${ }^{8}$ However, during diastole, subendocandial resistance vessels dilate and blood flow to this region is enhanced and transmural flow is distributed equitably. In this way, intramyocardial vascular tone modulates a tight coupling between oxygen requirements and oxygen supply. Factors responsible for regulating arteriolar tone are not known, but adenosine and other products of metabolism such as potassium ions have ready access to the intramyocardial vessels and are thought to have a regulator role..$^{9.10}$

Epicardial coronary arteries, in contrast, do not participate to any marked extent in flow autoregulation. Even at maximum blood flow rates (mammalian hearts are capable of a six-fold increase in coronary flow), the vessels are of sufficient calibre to permit flow without imposing significant resistance. However, it does appear that some variation in tone occurs and regulatory mechanisms exist. Coronary adrenergic alpha receptors " and bet $a_{1}$ and bet $a_{2}$ receptors ${ }^{12}$ have been identified and serotinergic and neuropeptidergic nerve fibres have been found in mammalian epicardial vessels. ${ }^{13,14}$ Also, high bloodflow states are thought to promote the release of vasodilators from the epicardial yascular endothelium. ${ }^{15,16}$ In addition, epicardial arteries are passively dilated when arterial pressure is elevated by manoeuvres such as exercise.

Atherosclerosis impairs the function of this perfusion system. Atherosclerosis involves only the epicardial vessels, not downstream resistance arterioles. ${ }^{17}$ Now the previously low-resistance epicardial transport arteries take

Department of Anesthesiology, Mayo Clinic, Rochester, Minnesota, U.S.A. 55905. 


\section{DYNAMIC CORONARY OBSTRUCTION}

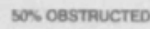

FIGURE 1 Representation of the importance of underlying coronary vascular tone in determining the hacmodynamic severity of an otherwise apparently fixed lesion. The vessel is 50 per cent obstructed by an atheromatous plaque. Frank spasm severely narrows the artery and converts the 50 per cent lesion to a 99 per cent lesion, and angina now occurs at rest. Incrensed vascular tone converts the 50 per cent lesion to a 75 per cent lesion. Symptoms now occur with exercise. Decreased vascular tone, as might be achieved with nitrates or calcium-antagonist drugs, reduces coronary vascular tone, decreases the degree of obstruction of the vessel, and abolishes symptoms. Underlying vascular tone is a component of "obstructive" coronary artery disease. (From Epstein and Talbot, ${ }^{3}$ with permission.)

on a new character - they impede coronary blood flow. Little disturbance in flow occurs at rest, even in the presence of severe lesions because compensatory downstream arteriolar dilatation occurs. Arteriolar dilatation can compensate to some degree for proximal epicardial coronary stenoses - this is vasodilator reserve. However, if myocardial oxygen requirements increase, resistance vessel dilation may not compensate adequately for the stenosis and myocardial ischacmia may ensue.

Untii recently, diseased coronary arteries were viewed as narrowed rigid tubes of fixed intraluminal diameter. Coronary stenoses were thought to produce a permanently fixed degree of vessel narrowing. It had been assumed that myocardial blood supply was permanently and unvariably restricted. Myocardial ischaemia was thought to result from increased myocardial oxygen demand in the setting of fixed, restricted supply. Resolution of ischaemia was thought to be a consequence of decreased oxygen needs, not of improvement in supply. These concepts have recently dramatically changed. ${ }^{3-3,18}$ Most atherosclerotic stenoses are eccentric - they do not completely encompass the vessel inner circumference. ${ }^{2,19}$ in 70 per cent of all atherosclerotic lesions, an arc of at least $60^{\circ}$ remains free of plaque thus permitting the vessel to contract and relax. Even changes in lumen diameter of
$0.1 \mathrm{~mm}$ to $0.2 \mathrm{~mm}$ can substantially alter the flow resistance of a high-grade proximal arterial lesions. Coronary stenoses are dynamic: atherosclerotic segments retain considerable capacity to dilate and also to constrict. They exhibit vasomotion so that even severely atherosclerotic vessels have been shown to undergo physiologically significant changes in their cross-sectional dimensions. 20,21 A small increase in stenosis diameter will profoundly decrease resistance to flow as, according to Poiseuille's law, resistance is inversely proportional to the fourth power of the vessel radius. A representation of the importance of underlying coronary smooth muscle tone in determining the degree of stenosis posed by an apparently fixed atherosclerotic lesion is shown in Figure 1 .

Not only does atherosclerosis raise plaques in the vessel lumen, it also damages the vascular endothelium. ${ }^{22}$ The vascular endothelium has a major role in regulating coronary artery tone. ${ }^{23,24}$ It does so by synthesizing and releasing vasodilator compounds such as prostacyclin and other as yet undefined relaxing factors (endothelium-dependent relaxing factor-EDRF). ${ }^{23.25} \mathrm{It}$ also modifies the effect of circulating factors and vasoactive agents released by blood components such as platelets. Its role in regulating vessel tone is thought to be an evolutionary adaptation. If the endothelium is damaged, such as during traumatic injury, substances released by blood coagulation have direct access to underlying vascular smooth muscle and cause vessel constriction. Blood loss is thus limited. If, on the other hand, clotting were to occur in a normal vessel, then the endothelium (intact in this normal vessel) would intercept the vasoconstrictors released in the process. They would not have ready access to the underlying smooth musele. In addition, the endothelium modifies the effect of many vasoactive substances, converting them from constrictors to dilators. Vessel dilatation would speed blood flow and help wash away the clot and dilute the clotting factors. The endothelium is, therefore, vital to normal functioning of epicardial vessels.

Coronary atherosclerosis damages the vascular endothelium (in some respects atherosclerosis resembles vessel injury). Damage, injury, and loss of the endothelium increases adherence of blood elements such as platelets, monocytes, macrophages, and mast cells at the site of the injury. ${ }^{22}$ These elements release a number of vasoactive substances, most of them potent vasoconstrictors such as serotonin, ${ }^{26}$ thromboxane $\mathrm{A}_{2},{ }^{27}$ histamine, ${ }^{28}$ and leukotrienes. ${ }^{29}$ The absence of functioning endothelium results in loss of protection of the underlying vascular smooth muscle. This smooth muscle is now directly exposed to circulating vasoconstrictors. Not only is this vascular barrier lost, but synthesis of vasodilators is also 


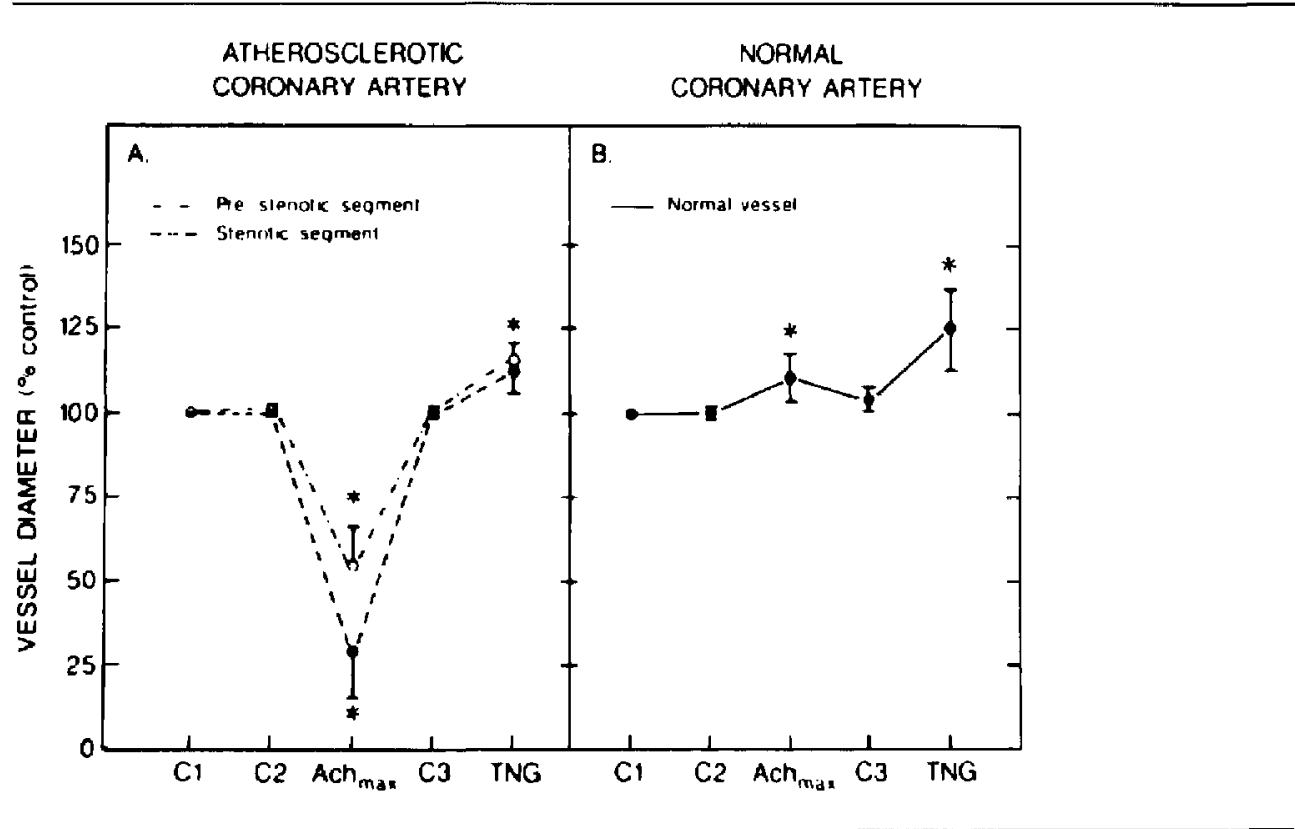

FIGURE 2 Responses of coronary arteries to intracoronary infusion of acetylcholine and nitroglycerin in patients with coronary artery disease. Atheroselerotic segment responses are shown on the left $(n=8)$ (Panel A). Normal segment responses are shown on the right ( $\mathrm{n}=4$ ) (Pancl $\mathrm{B}$ ). Vessel diameter was measured using quantitative coronary angiography. $\mathrm{Cl}$ denotes control, $\mathrm{C} 2$ vehicle control, Ach ${ }_{\max }$ response to maximal dose of acetylcholine, C3 repeated control, and TNG nitroglycerin. Asterisks indicate that $p<0.01$ for the comparison with Cl, Acetyleholine is an endothelium dependent vasodilator. Vasodilatation occurred in normal vessels. [n atherosclerotic vessels the response was constriction. (From Ludmer et al. ${ }^{30}$ with permission.)

halted. Derangement of endothelial function may explain a susceptibility to vasoconstriction that is currently believed to be present in typical coronary artery disease (CAD). ${ }^{18}$

Loss of protective endothelial function following atherosclerosis has recently been demonstrated in man (Figure 2). ${ }^{30,31}$ Acetylcholine was used as an example of a vasoconstrictor with endothelium-dependent effects. ${ }^{30}$ (It relaxes normal isolated canine rings but if the endothelium is damaged, these rings will contract.) Acetylcholine was infused directly into the coronary arteries of patients with CAD. Little change occurred in the calibre of normal segments of vessels but in atherosclerotic regions, marked epicardial coronary constriction occurred. The point is not that acetylcholine is a powerful constrictor of diseased coronary arteties (although it obviously is), but that normal regulation of coronary tone is lost following atherosclerosis. Atherosclerosis, dynamic coronary stenoses, and hypercontractility is a combination that renders the patient extremely vulnerable to myocardial ischaemia.

Factors that trigger dynamic changes in coronary tone are not well understood. In experimental animals, a number of naturally occurring substances such as serotonin, ${ }^{32}$ prostaglandins, leukotrienes, ${ }^{33}$ neuropeptides, ${ }^{34}$ and to a lesser degree alpha agonists ${ }^{32}$ produce epicardial coronary artery constriction. In man, no specific factors have been identified, although in susceptible patients coronary constriction can be induced with ergonovine, ${ }^{35}$ acetylcholine, ${ }^{30,31}$ histamine, ${ }^{36}$ and dopamine. ${ }^{37}$ There is a relationship between circadian thythm and susceptibility to angina although spontaneous variations in angina threshold can occur at any time of day. ${ }^{28}$

Quantitative coronary angiography has demonstrated that epicardial coronary constriction occurs during handgrip stress ${ }^{39}$ and bicycle exercise ${ }^{21}$ in patients with CAD. Normal segments of vessels are not constricted and may actually dilate. ${ }^{21}$ Exercise-induced constriction of atherosclerotic vessels and dilatation of normal vessels is shown in Figure 3. Beneficial effects of nitroglycerin are also demonstrated. Presumably, exercise alters neurohumoral tone and damaged coronary arteries respond inappropriately. Coronary constriction during exercise when myocardial oxygen consumption is elevated and flow demands 


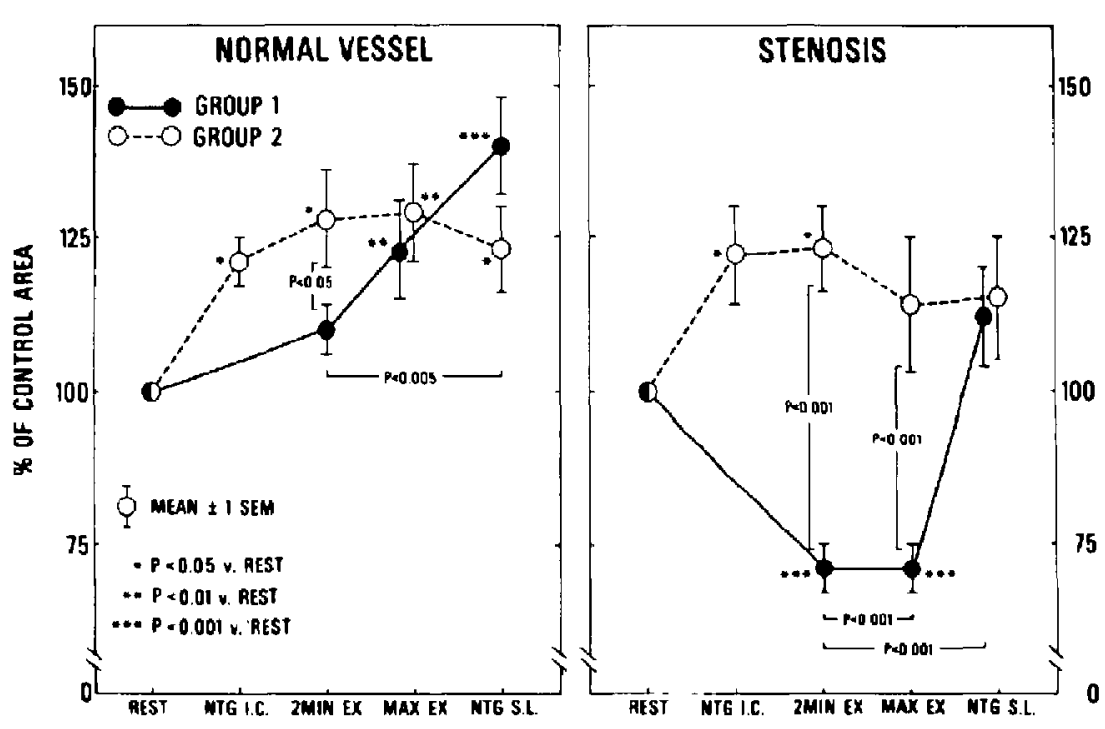

FIGURE 3 Changes in cross-sectional area (measured by quantitative angiography) of normal and stenutic segments of cpicardial coronary arteries in exercising patients. Group 1 patients received no pretreatment while Group 2 patients were pretreated with intracoronary nitroglycerin. Responses were expressed as percentage of Iesting luminal area. Normal vessels (left) dilated during exercise to 123 per cent of control values, and were further dilated by sublingual nitroglycerin (140 per ceni). Intracoronary nitroglycerin induced dilation of nomal vessels to 121 per cent of resting values and dilation persisted at the same level during subsequent exercise ( 129 per cent). In stenotic vessels (right), exercise induced a narrowing of stenoses to 71 per cent of control. Dilatation to 112 per cent of resting values occurred after sublingual nitroglycerin was given at the end of excrcise. Intracoronary nitroglycerin administered to Group 2 patients produced dilation of stenosis (122 per cent) that persisted during exercise (114 per cent), thereby preventing the exercise-induced narrowing of stenosis scen in Group 1 . $2 \mathrm{MIN}$ EX $=2$ min of supine bicycle exercise; MAX EX = the end of symptom-limited exercise; NTG IC = intracoronary nitroglycerin; NTG SL = sublingual nitroglycerin. (From Gage et al., ${ }^{21}$ with permission of the American Hear Association.)

are high is obviously detrimental. The degree that such dynamic constriction contributes to typical exertional angina is not known. Recent reports suggest that constriction superimposed upon atherosclerotic stenoses is a major factor in the generation of ischaemia. ${ }^{1,2,18,21,39} \mathrm{In}$ some respects, the stress of surgery resembles exercise stress as similar neurohumoral changes may accompany both situations. Whether or not coronary canstriction contributes to ischaemia during surgery is not known. Preliminary evidence suggests myocardial ischaemia does occur during anaesthesia in the absence of marked changes in myocardial oxygen demand, suggesting that oxygen imbalance may arise from a deficit in supply rather than increase in demand. 40,41

In the operating room, tone of both the large proximal and small distal coronary vessels can be readily manipulated. Although proximal vessel dilation (and prevention of constriction) is beneficial and would increase flow in the presence of coronary stenoses paradoxically, distal resistance vessel dilation may have adverse effects. ${ }^{2,3}$
Equitable distribution of flow within the myocardium is dependent upon appropriate arteriolar tone. If resistance vesse] dilation is induced in regions remote from the large vessel stenosis, flow may be distributed away from the potentially ischaemic zone. This phenomenon has been termed "coronary steal." 42 It has been suggested that isoflurane, ${ }^{43}$ nitroprusside, ${ }^{44}$ and dipyridamole ${ }^{6}$ are predominantly arteriolar resistance vessel dilators and these drugs have been associated with maldistribution of coronary flow and appearance or worsening of myocardial ischaemia. (The clinical implications of drug-induced coronary arteriolar dilatation remain controversial. ${ }^{45}$ )

Of all the drugs active on the coronary vasculature, nitroglycerin has an unsurpassed reputation for safety and effectiveness. No drug has better withstood the test of time. For many years there has been uncertainty concerning the mechanism of nitroglycerin's therapeutic effect. Undoubtedly, peripheral vasodilation with "unloading" of the heart and reduction in ventricular wall tension is an important therapeutic mechanism but in 


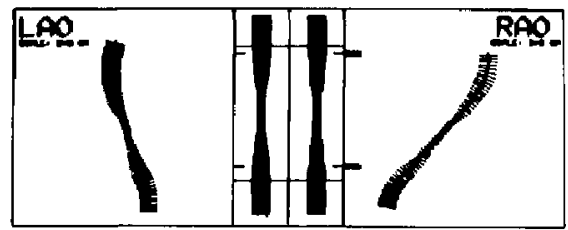

\section{CONTROL}

NORMAL MINIMUM MUNMUM FLOW
AREA DIAMETEP MREG RESISTANCE
AREA

$\left[\mathrm{mm}^{2}\right] \underset{\mathrm{mm}]}{[\mathrm{mm}}\left[\mathrm{mm}^{2} ;\left[\mathrm{mm} \mathrm{Hg} / \mathrm{sm}^{\mathrm{N}} / \mathrm{sec}\right.\right.$

AGSOLUTE $\quad 52 \quad 103 \quad 087 \quad 103$

$\%$ STENOSIS $\quad 60 \% \quad 63 \%$

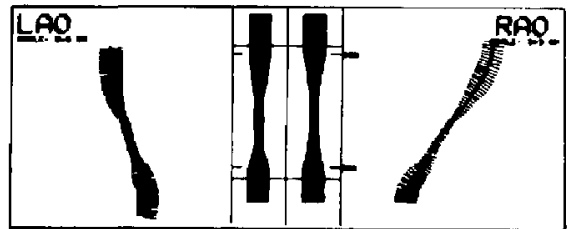

\begin{tabular}{|c|c|c|c|c|}
\hline \multirow[b]{2}{*}{ ABSOLUTE } & \multirow[b]{2}{*}{76} & \multicolumn{3}{|c|}{ N:T ROGLYCERIN } \\
\hline & & 118 & 112 & 65 \\
\hline \% STENOSIS & & $59 \%$ & $83 \%$ & \\
\hline $\begin{array}{l}\text { GMANGE } \\
\text { MIPOCWYYCF RIN }\end{array}$ & $\begin{array}{l}24 \\
146 \% 2\end{array}$ & $\begin{array}{l}015 \\
(15 \%)\end{array}$ & $\begin{array}{l}025 \\
(29 \%)\end{array}$ & $\begin{array}{l}-38 \\
(37 \%)\end{array}$ \\
\hline
\end{tabular}

FIGURE 4 Computet-enhanced jmage of a right coronary artery segment. Angiograms were performed before and after $0.4 \mathrm{mg}$ sublingual nitroglycerin. Nitroglycerin dilated both the normal and stenosed portions of the vessel. Actual stenosis cross-sectional area increased from $0.87 \mathrm{~mm}^{2}$ to $1.12 \mathrm{~mm}^{2}$, representing a 29 per cent increase in area. Nitroglycerin decreased calculated resistance to coronary flow by 37 per cent. LAO $=$ left anterior oblique; $\mathrm{RAO}=$ right anterior oblique. (From Brown er al. ${ }^{20}$ with permission of the American Heart Association.)

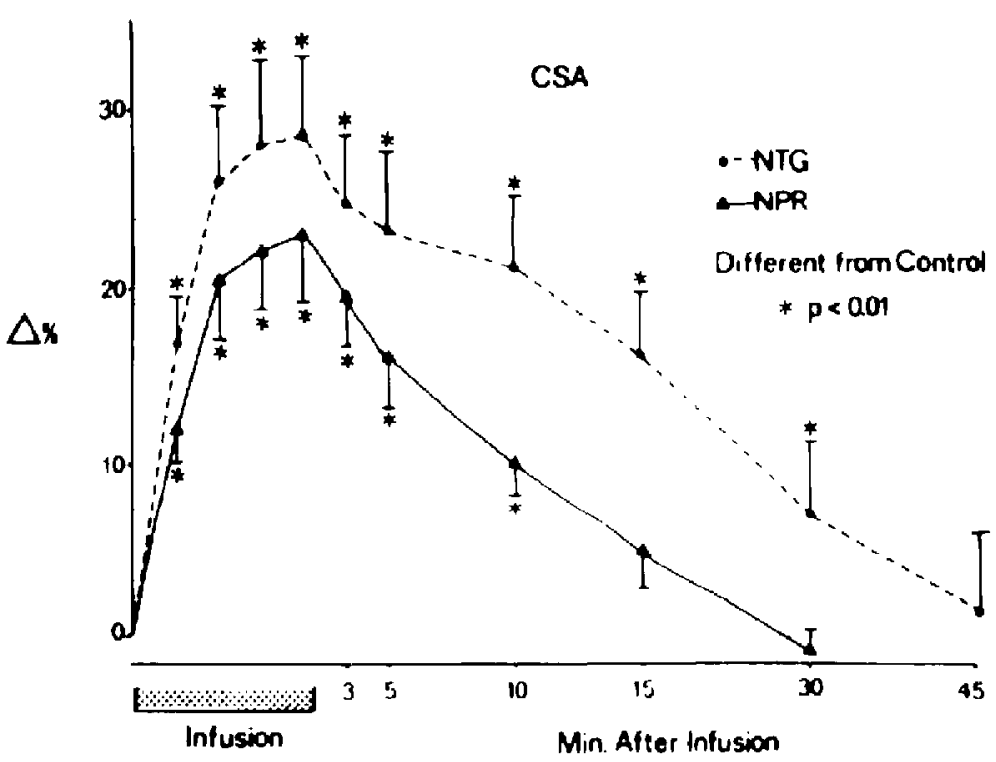

FIGURE 5 Effects of nitroprusside and nitroglycerin on circumflex coronary antery cross-sectional area (CSA) in the conscious dog. Implanted sonomicrometry crystals were used to measure dimensions. Nitroglyecrin induced significantly greater increase in CSA than nitroprussice although both drugs produced marked circumflex dilatation. (From Macho and Vatner, ${ }^{44}$ with permission of the American Heart Association.) 


\begin{tabular}{l|lllll|}
\hline & & & & & \\
\hline
\end{tabular}

FIGURE 6 Diltiazem and coronary constriction induced by handgrip exercise. Computer-generated images and measurements of a corunary urtery segment of one patient are illustrated. Various interventions are shown. $A n=$ area $\left(\mathrm{mm}^{2}\right)$ of the normal segment; $A$ min = area of the point with minimal cross-sectional area; $\mathrm{BP}=$ mean aortic pressure (mmHg): $\mathrm{HR}=$ corresponding heart rate (beats $\cdot \mathrm{min}^{-1}$ ); $\mathrm{CON}=$ control; HGP = handgrip; DILT = diltiazcm; NTG = nitroglycerin .

Diltiazem had litule effect on coronary artery cross-sectional area at res but did attenuate handgrip exercise induced constriction (in comparjson, nitroglycerin dilated the vessel at rest). (From Hossack et al. ${ }^{39}$ with permission of the American Heart Association.)

addition it is now quite apparent that epicardial coronary dilatation is also a major factor. High resolution computerenhanced coronary angiography in patients with coronary artery disease has conclusively demonstrated that nitroglycerin not only dilates diseased coronary segments, but also prevents coronary constriction. ${ }^{20,21,46}$ Figure 3 shows nitroglycerin's effectiveness both in preventing and treating coronary constriction: actual coronary dilatation occurs. Epicardial coronary dilatation is again demonstrated in Figure 4. Epicardial coronary artery dilatation is achieved with little effect on distal coronary arterioles; therefore, nitroglycerin is unlikely to cause steal. Nitroglycerin is perhaps the ideal coronary vasodilator.

Nitroprusside, in contrast, dilates both large and small coronary vessels. ${ }^{44}$ Epicardial coronary arteries are dilated in both dogs and man; however, the magnitude of this effect is probably less than that achieved with nitroglycerin. This effect is shown in Figure 5. Nitroprusside dilates coronary arterioles and, therefore, may potentially cause steal and induce or worsen myocardial ischaemia. Whether or not such an effect occurs clinically has not yet been conclusively determined. ${ }^{45}$

Calcium antagonist drugs, while not being particularly effective as proximal coronary artery dilators per se, are nevertheless extremely effective in preventing constriction. ${ }^{39}$ Nifedipine, verapamil, or diltiazem produce only slight epicardial coronary dilatation, far less than does nitroglycerin but all are effective in preventing coronary spasm. Prevention of excrcisc-induced atherosclerotic coronary artery constriction by diltiazem is illustrated in Figure 6. Calcium antagonists are generally also coronary arteriolar dilators 5 but surprisingly, these drugs are not associated with the steal phenomenon, maldistribution of coronary blood flow, nor appearance of myocardial ischaemia. Of the calcium antagonists, nisoldipine is perhaps one of the most potent coronary arteriolar dilators in man. ${ }^{47}$

Perioperative drug therapy may cause epicardial coronary constriction. Histamine release is not uncommon during anaesthesia and surgery and has complex effects on the coronary vasculature. ${ }^{36}$ In man, $\mathrm{H}_{1}$ receptor stimulation is thought to induce coronary arteriolar dilatation and, in addition, in susceptible patients may simultaneously cause epicardial coronary artery constriction. Such opposite changes in tone can both predispose to ischaemia (this difference in response of the two types of vessels emphasizes their different regulatory mechanisms). Dopamine has recently been shown to constrict epicardial coronary arteries in susceptible patients. ${ }^{37}$ The mechanism is unknown but it has been suggested that seroton-

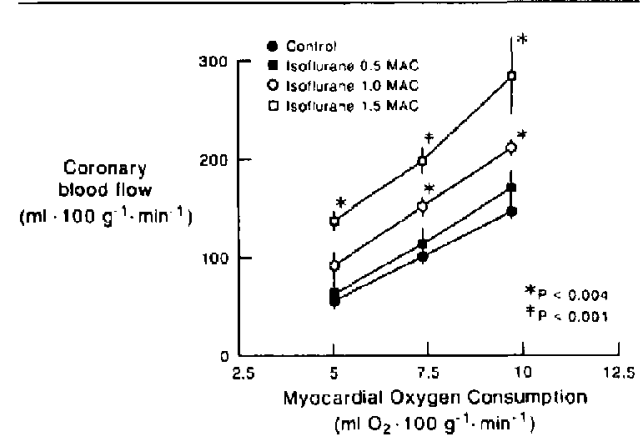

FIGURE 7 Effects of isoflurane on coronary blood flow in dogs. Plots of coronary blood flow versus myocardial oxygen consumption are shown. Lines represent blood flow calculated at three standard $\mathrm{MVO}_{2}$ rates $-5,7.5$, and $10 \mathrm{ml} \mathrm{O} \mathrm{O}_{2} \cdot 100 \mathrm{gml}^{-1} \cdot \mathrm{min}^{-1}$. Four lines are shown, one indicating control data and the other three representing data following 0.75 per cent, 1.50 per cent ( 1 MAC in the dog), and 2.25 per cent isoflurane. Isofurane displaced the lines upwards. At a given rate of $\mathrm{MVO}_{2}$, coronary flow is greater following isoflurane. Arteriolar dilatation has occurred. Values are mean $\pm S E(n=8)$. A Bonferroni correction of $p<0.05$ per 3 comparisons $(p<0.016$ ) was considered significant. (From Sill JC, Bove AA, Nugent M et al., ${ }^{4}$ with permission.) 


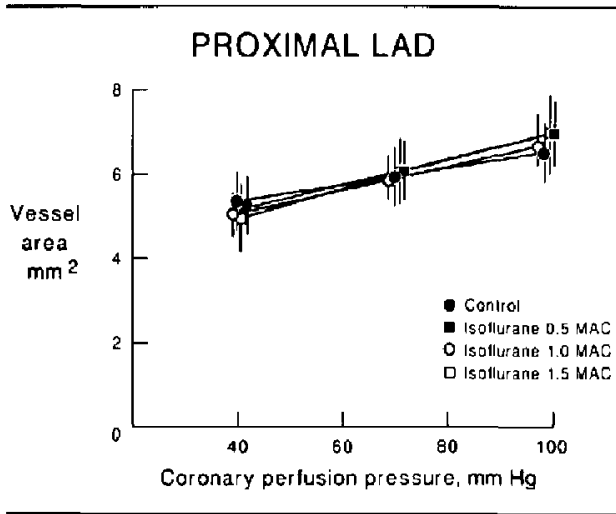

FIGURE 8 Isoflurane and epicardial coronary dimensions. Crosssectional area of canine proximal left anterior descending coronary arteries versus coronary perfusion pressure. Asea was measured using computer assisted coronary angiography. Vessel area was calculated at the three standard perfusion pressures: $40 \mathrm{mmHg}, 70 \mathrm{mmHg}$, and $100 \mathrm{mmHg}$. Four lines on each graph are shown, one indicating control data and the other three representing data following 0.75 per cent, 1.50 per cent ( $1 \mathrm{MAC}$ in the dog) and 2.25 per cent isoflurane. All four lines are close together and are at times superimposed, demonstrating that isolurane neither dilated nor constricted the coronary artery. Values are mean $\pm S E(n=7)$. (From Sill JC er al., ${ }^{48}$ with permission.)

ergic receptor stimulation may be responsible. Phenylephrine is an alpha agonist which is useful in anaesthetized patients. Whether or not it causes epicardial coronary constriction in patients with coronary disease is unknown. In dogs, it produces only minor epicardial coronary constriction. ${ }^{32}$ Alpha agonists are not thought to be major epicardial coronary constrictors in man and alpha blockade has not proven to be an effective treatment for Prinzmetal angina.

Anaesthetic drugs have very definite effects on the coronary yasculature. Isoflurane has been shown to be a potent coronary arteriolar dilator. ${ }^{43,48}$ The clinical significance of this effect is yet to be determined as isoflurane has both been implicated in the genesis of myocardial ischaemia ${ }^{49}$ and has been shown to protect the stressed heart against ischaemia. ${ }^{50}$ In the dog, we have shown coronary arteriolar dilatation to be dose-dependent and although 1.5 MAC isoflurane caused a marked increase in coronary blood flow, 0.5 MAC concentrations had little significant vasodilating effect (Figure 7). Halothanc, ${ }^{51}$ enflurane, ${ }^{52}$ and nitrous oxidc ${ }^{53}$ do not alter coronary arteriolar tone. Epicardial coronary arterics in the dog are not dilated by isoflurane (Figure 8). ${ }^{48}$ However, when isolated canine coronary rings are exposed to constrictors, isoflurane does attenuate contraction. Attenua-

\section{EFFECT OF ISOFLURANE ON RESPONSE OF CANINE CORONARY ARTERIES}

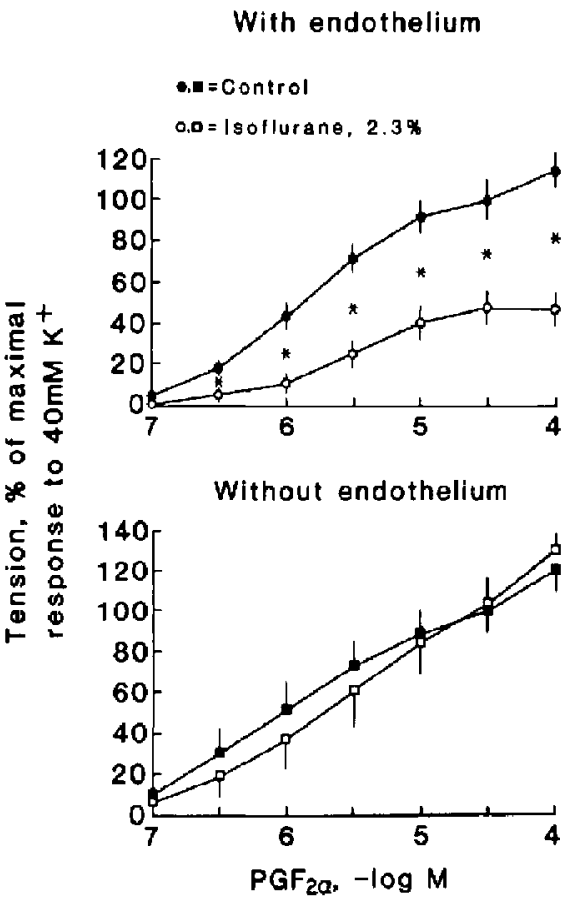

FIGURE 9 Effects of isoflurane ( 2.3 per cent) on the cumulative concentration response curve of isolated canine coronary anery rings suspended in organ chambers. Rings on the left had nomally functioning endothelium while rings on the right had been denuded of endothelium. Rings were exposed to inereasing concentrations of the vasoconstrictor prostaglandin $F_{2} \alpha$. Contractions are expressed as percentage of contractile response to $\mathrm{KC} \perp(40 \mathrm{mM})$. Data shown as mean $\pm \operatorname{SEM}(n=6)$. *Denotes that the effect of isoflurane is statistically significant $(p<0.005)$. In the presence of normally functioning endothelium ring contraction was attenuated by isoflurane. Damage to the endothelium resulted in loss of isoflurane effect. (From Blaise et al ${ }^{34}$ with permission.)

tion of coronary ring contraction by isoflurane is shown in Figure 9. The mechanism appears to be endotheliumdependent as the effect is lost if the vessel endothelium is damaged ${ }^{34}$ Nitrous oxide, in contrast to isoflurane, constricts canine epicardial coronary arteries. The mechanism is unknown. ${ }^{55}$ Nitrous oxide-induced coronary artery constriction is shown in Figure 10. Whether or not a similar effect occurs in humans is also unknown. 


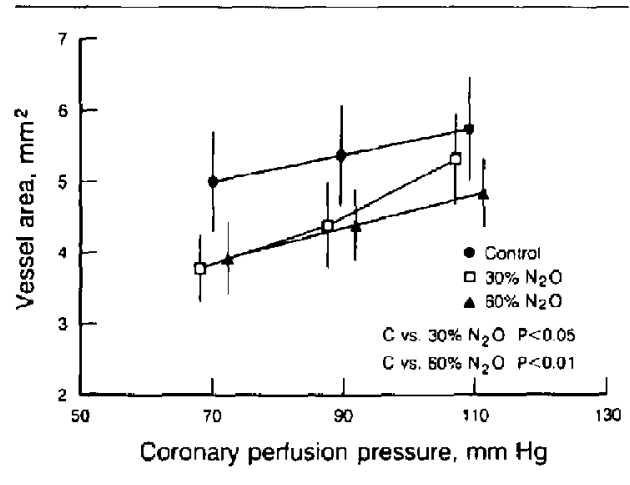

FIGURE 10 Nitrous oxide und epicardial coronary dimensions. Cross-sectional area of a canine proximal circumflex coronary artery versus coronary perfusion pressure. Area was measuredi using computerassisted coronary angiography, Vessel areas were calculated at three standard perfusion pressurcs; $70 \mathrm{mmHg}, 90 \mathrm{mmHg}$, and $100 \mathrm{mmHg}$. Three lines are shown on each graph, one representing control data, and two representing data following 30 per cent nitrous oxide and 60 per cent nitrous oxide. The nitrous oxide lines fall below the control lines demonstrating constriction of the coronary artery. Statistical dif. fcrences between control line and lines following nitrous oxide admin istration are shown. Values are mean $\pm \mathrm{SE}(\mathrm{n}=9)$. (From Sill et al., with permission.)

When caring for patients with CAD, our aims in the past have been to maintain adequate perfusion pressure, slow the heart rate, depress contractility, and unload the ventricle. To this list of aims must now be added the need to also maintain appropriate cpicardial coronary artery and intramyocardial arteriolar tone.

\section{References}

I Maseri A, Chierchia S, Kaski JC. Mixed angina pectoris. Am J Cardiol 1985; 56: 30E.

2 Brown BG, Bolson EL, Dodge HT. Dynamic mechanisms in human coronary stenosis. Circulation 1984; 70: 917.

3 Epstein SE, Cannon RO, Talbot TL. Hemodynamic princi ples in the control of coronary blood flow. Am J Cardiol 1985; 56: $4 \mathrm{E}$.

4 McGregor $M$. The nitrates and myocardial ischemia. Circulation 1982; 66: 689 .

5 Vanhoutte PM, Cohen RA. Calcium-entry blockers and cardiovascular disease. Am J Cardiol 1983; 52: 99A.

6 Brown BG, Josephson MA, Petersen RB et al. Intravenous dipyridamole combined with isometric handgrip for near maximal acute increase in coronary flow in patients with coronary artery disease. Am J Cardiol 1981; 48: 1077.

7 Boucek RJ, Morales AR, Romanelli R, Judkins MP, Coronary blood flow. In: Coronary Artery Disease, Pathologic and Clinical Assessment. Baltimore, 1984, Williams \& Wilkins, 131-40.

8 Shepherd JT, Vanhoutte $P M$. The human cardiovascular system: facts and concepts. New York, Raven Press, 1979 , 91-106.

9 Wilcken DEL. Local factors controlling coronary circulation. Am J Cardiol 1983; 52: 8A.

10 McKenzie JE, Steffen RP, Haddy FJ. Relationships between adenosine and coronary resistance in conscious exercising dogs. Am J Physiol 1982; 242 : H24.

11 Vatner SF, Pagani M, Manders WT, Pasipoularides AD. Alpha adrenergic vasoconstriction and nitroglycerin vasodilation of large coronary arteries in the conscious dog. $\mathrm{J}$ Clin Invest $1980 ; 65: 5$.

12 Vatner DE, Knight DR, Homcy Cl, Vather SF, Young MA. Subtypes of beta-adrenergic receptors in bovine coronary arteries. Circ Res 1986; 59: 463.

13 Polak $J M$, Blood SR. Regulatory peptides: key factors in the control of bodily functions. Br Med J 1983;286: 1451 .

14 Said SI. Vasoactive peptides: state of the art review. Hypertension 1983; 5 (Suppl I): 17.

15 Macho P. Hintze HT, Vamer SF. Regulation of large coronary arteries by increases in myocardial metabolic demands in conscious dogs. Circ Res 1981; 49 : 599.

16 Holtz J, Forstermann U, Pohl U, Giesler M. Bassenge E. Flow-dependent, endothelium-mediated dilation of epicardial coronary arteries in conscious dogs: effects of cyclooxygenase inhibition. J Cardiovasc Pharmacol 1984; 6: 1161.

17 Halon DA, Sapoznikov D, Lewis BS et al. Localization of lesions in the coronary circulation. Am J Cardiol 1983; 52: 921 .

18 Brunwald E. A symposium: experimental and clinical aspects of coronary vasoconstriction. Am J Cardiol 1985; 56: $1 \mathrm{E}$.

19 Freudenberg $H$, Lichtlen $P R$. The normal wall segment in coronary stenosis - a postmortem study. Z Kardiol 1981; 70: 863 .

20 Brown BG. Bolson E. Petersen RB. Pierce CD, Dodge $H T$. The mechanisms of nitroglycerin action: stenosis vasodilatation as a major component of the drug response. Circulation 1981; 64: 1089.

21 Gage JE, Hess OM, Murakami T, Ritter M, Grimm J, Krayenbughl HP. Vasoconstriction of stenotic coronary arteries during dynamic exercise in patients with classic angina pectoris: reversibility by nitroglycerin. Circulation 1986; 73:865.

22 Ganz $P$. Alexander $R W$. New insights into the cellular mechanisms of vasospasm. Am J Cardiol 1985; 56: $11 \mathrm{E}$

23 Vanhount PM, Rubanyi GM, Miller VM, Houston DS. Modulation of vascular smooth muscle contraction by the endothelium. Ann Rev Physiol 1986; 48: 307. 
24 Furchgort $R F$. Role of endothelium in responses of vascular smooth muscle. Circ Res 1983; $53: 557$.

25 Griffith TM, Edward DH, Lewis MJ, Newby AC, Hender$\operatorname{son} A H$. The nature of endothelium-derived vasculat relaxant factor. Nature 1984; 308: 645-7.

26 Cohen RA, Shepherd JT, Vanhoutte PM. Inhibitory role of the endothelium in the response of isolated coronary arteries in platelets. Science 1983:221: 273.

27 Ellis EF, Oeiz O, Roberts $L J$ et al. Coronary arterial smooth muscle contraction by a substance released from platelets: evidence that it is thromboxane $A_{2}$. Science 1976 ; 193: 1135 .

28 Ginsburg $R$, Brisfow MR, Kantrowitz N, Baim DS, Harrison $D C$. Histamine provocation of clinical coronary artery spasm: implications concerning pathogenesis of variant angina pectoris. Am Heart J 1981; 102: 819.

29 Ezra D, Boyd LM, Feuerstein $G$, Goldstein RE. Coronary constriction by leukotriene $C_{4}, D_{4}$, and $E_{4}$ in the intact pig heart. Am J Cardiol 1983; 51: 1451.

30 Ludmer PL, Selwyn AP, Shook EL et al. Paradoxical vasoconstriction induced by acetylcholine in atherosclerotic coronary arteries. N Engl J Med 1986; 315: 1046.

31 Yasue $H$, Horio $Y$, Natusuki $N$ et al. Induction of coronary artery spasm by acetylcholine in patients with variant angina: possible role of the parasympathetic nervous system in the pathogenesis of coronary artery spasm. Circulation 1986; 74 : 955.

32 Bove $A A$, Dewey $I D$. Effects of serotonin and histamine on proximal and distal coronary vasculature in dogs: comparison with alpha-adrenergic stimulation. Am J Cardiol 1983; 52: 1333.

33 Ezra D, Feuerstein G, Rumwell PW, Hayes E, Goldstein $R E$. Effects of platelet-activating factor on coronary hemodynamic and coronary venous plasma levels of $\mathrm{TXB}_{2}$ 6-keto-PGF $1 \alpha$, and leukotriene $\mathrm{C}_{4}$ immunoreactivity in the intact domestic pig heart. In: Advances in Prostglandin Thromboxane and Leukotriene Research. Neri-Semeri GG, et al. (Eds). New York, Raven Press, Va1. 13, 1985, 19-21.

34 Edvinson L, Ekblad E, Hakanson R, Wahlestedt $C$. Neuropeptide $\mathrm{Y}$ potentiates effect of various vasoconstrictor agents on rabbit blood vessel. Br J Pharmacol 1984; 83: 519.

35 Fester A. Provocalive testing for coronary arterial spasm with ergonovine maleate. Am J Cardiol 1980; 46: 338

36 Vigorito C, Poto S, Picotti GB, Triggiani M, Marone $G$. Effect of activation of the $H_{1}$ receptor an coronary hemodynamics in man. Circulation 1986; 73: 1175.

37 Crea F, Chierchia S, Kaski JC at al. Provocation of coronary spasm by dopamine in patients with active variant angina pectoris. Circulation 1986; 74: 262
38 Figueras $J$, Cinca J, Balda $F$, Moya A, Rius $J$. Resting angina with fixed coronary artery stenosis: nocturnal decline in ischemic threshold. Circulation 1986; 74: 1248.

39 Hassack KF, Brown BG, Steward DK, Dodge HT. Diliazem-induced blockade of sympathetically mediated constriction of normal and diseased coronary arteries: lack of epicardial coronary dilatory effect in humans. Circulation 1984; $70: 465$

40 Kleinman B, Henkin RE, Glisson er al. Qualitative evaluation of coronary flow during anesthetic induction using thallium-201 perfusion scans. Anesthesiology 1986; 64: 157.

41 Merin RG, Lowenstein E, Gelman S. Is anesthesia beneficial for the ischemic heart? III. Anesthesiology 1986; 64: 137.

42 Becker $L C$. Conditions for vasodilator-induced coronary steal in experimental myocardial ischemia. Circulation 1978; 57: 1103.

43 Buffington CW, Romson JL, Durtlinger NC. Does isofurane cause coronary steal? Anesthesiology 1985; 63: A9.

44 Macho P, Vatner SF. Effects of nitroglycerin and nitroprusside on large and small coronary vessels in conscious dogs. Circulation 1981; 64: 1101 .

45 Feldman RL, Conti CR, Pepine CJ. Comparison of coronary hemodynamic effects of nitroprusside and sublingual nitroglycerin with anterior descending coronary arterial occlusion. Am J Cardiol 1983; 52: 915

46 Feldman RL, Pepine CJ, Conti CR. Magnitude of dilatation of large and small coronary arteries by nitroglycerin. Circulation 1981; $64: 324$

47 Soward AL, De Feyter PJ, Hugentoltz PG, Serruys PW. Maintenance of increascd coronary blood flow in excess of demand by nisoldipine administered as an intravenous infusion. Am J Cardiol 1986; 58; 1204

48 Sill JC, Bove AA, Nugent M, Blaise GA, Dewey JD, Grabau $C$. Effects of isoflurane on coronary arteries and coronary arterioles in the intact dog. Anesthesiology. In Press.

49 Reiz $S$, Baljors $E$, Sorensen $M$, Ariola $S$, Friedman A, Iruedsson $\boldsymbol{H}$. Isoflurane - a powerful coronary vasodilator in patients with coronary artery disease. Anesthesiology 1983; 59: 91 .

50 Tarnow J, Markschies-Hornung A. Schulte-Sasse U. Isofurane improves the tolerance to pacing-induced myocardial ischemia. Anesthesiology 1986; 64: 147.

51 Merin RG, Kumazawa T, Luka NL. Myocardial function and metabolism in the conscious dog and during halothane anesthesia. Anesthesiology 1976; 44: 402 .

52 Merin RG, Kumazawa T, Luka NL. Enfurane depresses myocardial function, perfusion, and metabolism in the dog Anesthesiology 1976; 45: 501 . 
53 Philbin DM, Föex P. Drummond G. Lowenstein $E$, Ryder $W A$, Jones $L A$. Postsystolic shortening of canine left ventricle supplied by a stenotic coronary artery when nitrous uxide is added in the presence of narcotics. Anesthesiology 1985; 62: 166.

54 Blaise GA, Sill JC, Nugent $M$, Van Dyke RA, Vanhoutse $P M$. Endothelial damage abolishes isoflurane attenuation of $\mathrm{PGF}_{2} \mathrm{Ir}$ and $5 \mathrm{HT}$-mediated canine coronary constriction Anesthesiology 1986;65: A7

55 Sill JC, Wilkowski DAW, Bove AA, Owen R, Bonta W. Nitrous oxide constricts epicardial coronary arteries in intact dogs. Ancsthesiology 1986; 65: A513. 